\title{
Study on the relationship between economic development and air pollution in Shaanxi Province Based on GPI index
}

\author{
Sun $\mathrm{Yu} \mathrm{Ze^{1 }}$ \\ ${ }^{1}$ Xi'an University of technology, Xi'an, Shaanxi, China \\ a634984801@qq.com \\ *Sun yu ze
}

Keywords: GDP ; Air pollution; GPI index

\begin{abstract}
With the rapid development of China's economy, the conflict between environment and economic development is also constantly occurring. As the central region of Western China, economic development and environmental pollution in Shaanxi are becoming more and more prominent. For this purpose, this paper makes an empirical analysis on the relationship between economic growth and air pollution in Shaanxi province by using the relevant data of Shaanxi province from 2005 to 2015 and citing the concept of GPI index. The results show that the GPI of $\mathrm{SO} 2$ and smoke are negatively correlated with GDP.
\end{abstract}

\section{基于 GPI 指数的陕西省经济发展与空气污染关系研究 孙语泽 1 \\ 1 西安理工大学, 西安, 陕西, 中国 a634984801@qq.com \\ *孙语泽}

关键词: GDP; 大气污染; GPI指数

摘要：随着我国经济日益快速发展，环境与经济发展之间的冲突也在不断发生。作为我国西 部的中心区域, 陕西省经济发展与环境污染问题也变得越来越突出。为此本文利用陕西省2005 - - 2015年的相关数据, 引用GPI指数理念, 对陕西省的经济增长与大气污染之间的关系进行 了实证分析。结果表明，陕西省 $\mathrm{I}_{\mathrm{GPIsO2}}$ 、 $\mathrm{I}_{\mathrm{GPIsmo}}$ 与 GDP之间均为负相关。

\section{1. 引言}

一直以来，环境恶化是世界各国经济发展亟待解决的首要难题。自我国改革开放成功实 施之后, 伴随着经济的高速增长, 环境污染也极具加重, 对于正处在工业化中期的陕西省来 说, 空气污染问题更是突出：大气质量每况愈下，雾雽问题愈来愈严重。因此陕西省急需找 到促使经济与空气质量互利共赢的可持续发展道路。如果长期只片面追求 GDP 的增长而不重 视由于经济发展所带来的环境污染问题, 那么未来环境污染引发的一系列问题将会对经济发 展造成反制效应。因此, 如何提高经济发展的质量, 降低单位 GDP 污染物的产生就成为实现 可持续发展的重点。本文将利用 GPI 指数, 通过实证方法对陕西省空气污染与经济发展之间 进行定量分析, 为实现陕西省环境与经济可持续发展提供理论依据。

\section{GPI指数}

GPI 指数，全称为国内生产总值污染物排放指数(GDP Pollutant Emission Index)，指的是 
在一定时间一个国家（或地区）每创造出一单位国内生产总值（GDP）时对应释放出的污染 物数量。一般以下几点因素会影响 GPI 数值的大小: 研究区域地理位置和自然资源状况; 研 究区域发展态势; 研究区域经济结构; 研究区域管理层在环境保护方面所持态度。GPI 指数 能够极具综合性的分析出经济与环境体系协调发展程度, 其对于研究区域环境与经济之间可 持续发展领域更是具有重大的参考价值。

其计算式为:

$$
\mathrm{GPI}=\frac{\text { 污染物排放量 }}{\mathrm{GDP}}
$$

在衡量大气污染的诸多污染物指标中, $\mathrm{SO}_{2}$ 排放量和烟尘排放量两项指标所占比重最大, 因此本文将从 $\mathrm{SO}_{2}$ 排放量、烟尘排放量两项入手分别计算出陕西省大气环境 $\mathrm{SO}_{2}$ 排放量、烟 尘排放量的 GPI 指数, 由此分析陕西大气污染现状。

\section{3. 陕西省GPI指数实证分析}

\section{1 数据选取}

公式（1）中所需的 GDP 值定为陕西省 2005-2015 年在《中国统计年鉴》及《陕西统 计年鉴》发布的 GDP 数据, 单位为: 亿元。由图所示, 可以看出 2005-2015 年陕西省经 济指标持续走高, GDP 长期处于稳步上涨状态, 虽然到 2014 年增速有所下降, 但仍旧保持 上升趋势。

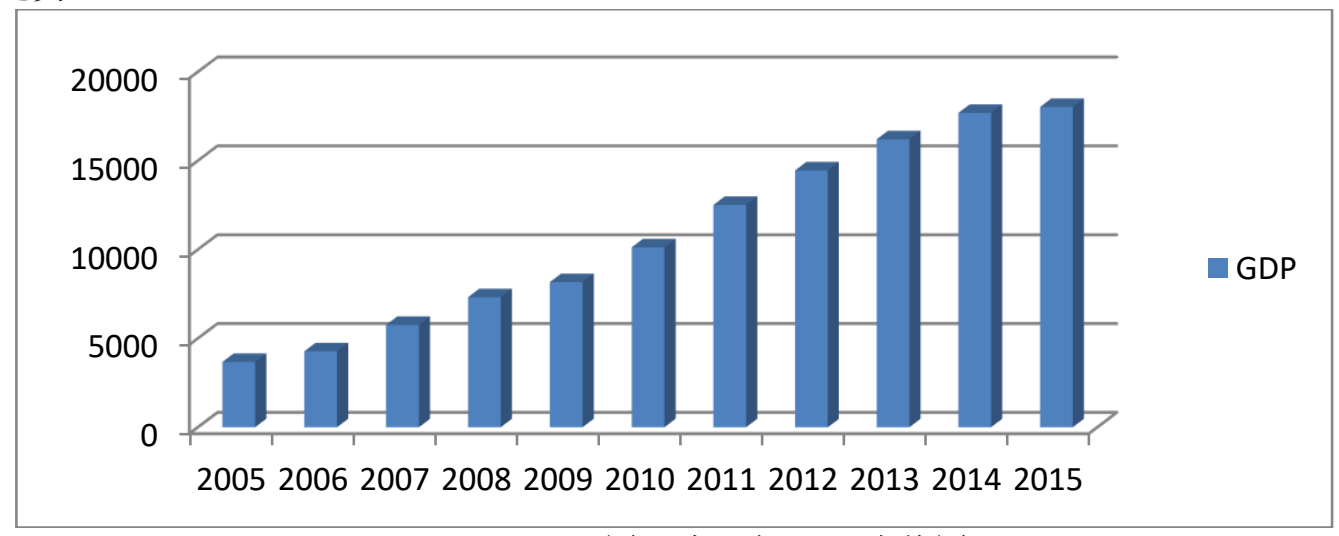

图 1.陕西省 GDP 走势图

公式 (1) 中所需污染物排放量值选择 2005-2015 年陕西省 $\mathrm{SO}_{2}$ 排放量和烟尘排放量, 单位为万吨，该两项数据均选自《中国环境统计年鉴》。据图所示，陕西省二氧化硫排放量除 了在 2005-2006 年以及 2010-2011 年有所上涨之外，总体呈变小趋势; 烟尘排放量在 近十年间总体变化趋势不甚乐观, 仅在 2005 至 2010 年表现出较强的变小趋势, 自 2010 年之 后出现大幅上涨, 直到 2014 年开始下降。陕西省政府仍然需要加强环保工作力度, 在保持二 氧化硫排放量稳步下降趋势前提下，重视烟尘排放量的减排工作。 


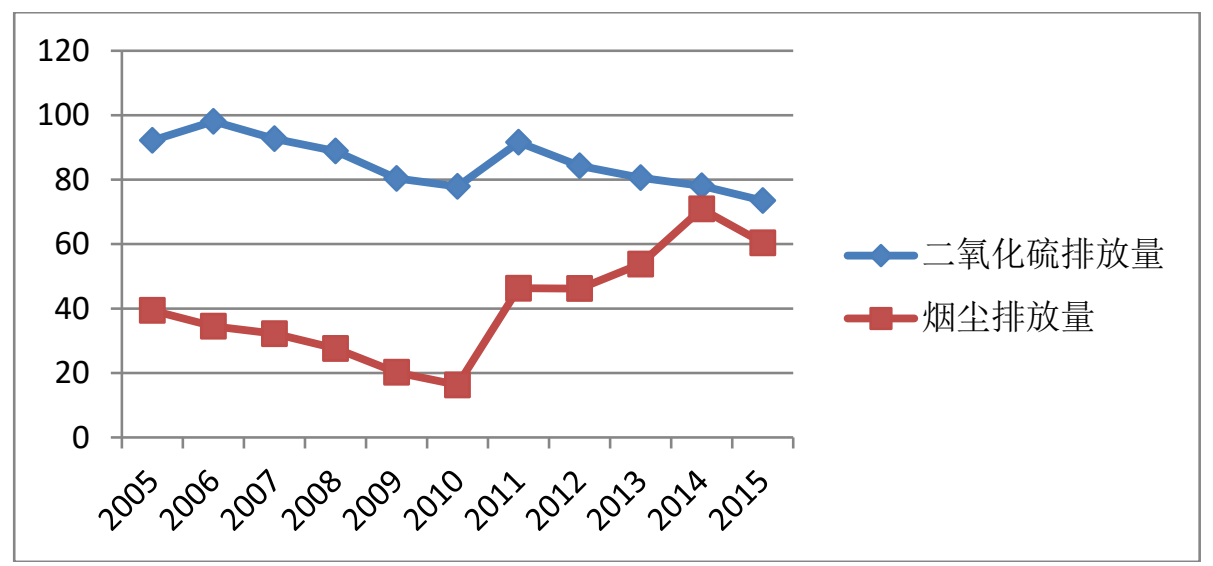

\section{2 实证结果及分析}

图 2.二氧化硫、烟尘排放量变化示意图

根据公式 (1), 将 2005-2015 年陕西省二氧化硫排放量和烟尘排放量分别带入，计算 出二者各自的 GPI 指数, 如下所示。

$$
\begin{gathered}
I_{\mathrm{GPISO} 2}=I \mathrm{SO} 2 / I_{\mathrm{GDP}} \\
I_{\mathrm{GPISMO}}=I_{\mathrm{SO} 2} / I_{\mathrm{GDP}}
\end{gathered}
$$

上述公式中： $\mathrm{I}_{\mathrm{GPI} \text { so2 }}$ 指的是单位 GDP 中二氧化硫排放量, $\mathrm{I}_{\mathrm{GPI} \text { sо }}$ 为单位 GDP 中烟尘的排 放量, $\mathrm{I}_{\mathrm{SO} 2}$ 为二氧化硫排放总量, $\mathrm{I}_{\mathrm{SMO}}$ 为烟尘排放总量。计算所得的 GPI 值愈小, 说明陕西经 济与大气环境系统协调发展程度愈高; 反之, GPI 值愈大, 说明陕西经济与大气环境系统协 调发展程度愈小。

经 EXCEL2007 统计软件计算分别得到陕西省 2005-2015 年 $\mathrm{I}_{\mathrm{GPISO}}$ 和 $\mathrm{I}_{\mathrm{GPI}_{\mathrm{SMO}}}$ 变化如下表:

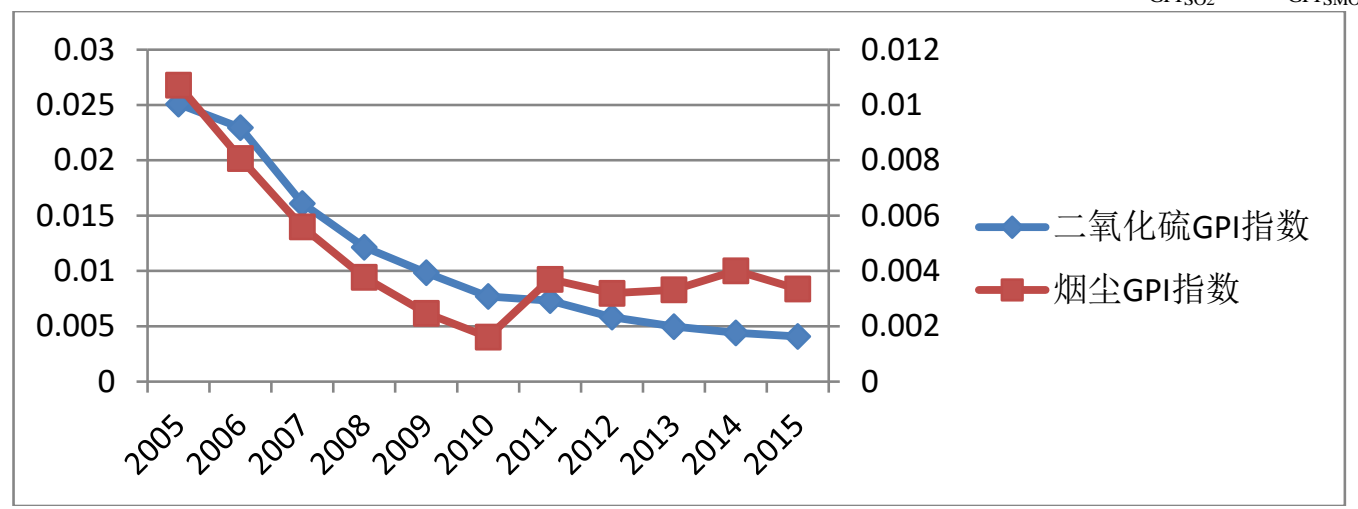

图 3. 二氧化硫、烟尘排放量 GPI 指数值

分别来看, $\mathrm{I}_{\mathrm{GPI} \mathrm{SO2}}$ 自 2005 年 (0.025) 起一直保持下降势头, 直到 2015 年 (0.004) 累计 下降幅度 0.021 , 平均值为 0.011 。自 2008 年之后陕西省 $\mathrm{I}_{\mathrm{GPI} \text { So2 }}$ 值均处在平均值之下, 虽然后 期增速减缓, 但仍然保持降低趋势; $I_{\text {GPIsmo }} 2005$ 年（0.011）至 2015 年 (0.003) 总的下降幅 度为 0.008 , 总的平均值为 0.005 , 相比 $\mathrm{I}_{\mathrm{GPI}_{\mathrm{s} O 2}}$ 来说变化幅度较小。但从 2008 年 $(0.004)$ 之后 $\mathrm{I}_{\mathrm{GPI}_{\mathrm{Smo}}}$ 也一直保持平均值以下，虽然在 2010-2011 年期间略有小的上浮，但总趋势不变，仍是向 下的。

总的来说, 在 GDP 相对高的阶段, 对应的 GPI 指数大体上处于低水平状态, 在经济发展 程度较高时, 单位 GDP 中二氧化硫排放量、烟尘排放量较小, 当经济发展程度较低时, 单位 GDP 中二氧化硫排放量、烟尘排放量较大。两项排放物的 GPI 指标值虽然呈波动迹象，但基 
本上都与 GDP 之间均呈现负相关关系。

陕西省现如今产业结构仍然处在以第二产业为核心、第三产业发展滞后的不成熟阶段, 重工业依然主导陕西工业经济，尤其是煤炭开采业、有色金属矿采选业、石油加工和炼焦及 核燃料加工业、电力和热力供给业、有色金属冶炼及压延加工业、化学成品制造业、医药制 造业和黑色金属冶炼及压延加工业。这些企业对于陕西大气污染仍有着不可忽视的影响，是 阻碍陕西大气质量良性发展的主要因素, 陕西省必须加快转变产业结构布局, 加强低碳产业、 清洁能源产业的发展, 降低第二产业比重, 并且发挥出地理区位优势, 大力推进枢纽经济发 展, 寻求经济新增长点, 只有这样才可形成大气环境与经济增长互利发展。

\section{4. 结论}

本文基于 2005-2015 年陕西省的二氧化硫排放量、烟尘排放量以及 GDP 数据, 通过 引用 GPI 指数理念, 对于陕西省经济发展与大气污染之间的关系进行了实证分析, 结果表明, 目前陕西省的大气污染与经济之间的发展正在向着共赢的发展方向前进。但是污染物的排放 量方面, 陕西省与国内发达地区相比仍然较高, 在减排方面陕西省政府仍要加大投入力度, 实施污染物排放总量控制体系，从根本上降低排污负荷，提高公众节能减排自觉性。

\section{References}

[1] Zhao P, Wu Y, Dong X L. Study on the Relationship between Economic Growth and Environmental Pollution in Shaanxi - Based on the Pollutants Emission Index of Gross Domestic Product(GDP)[J]. Journal of Xi'an Shiyou University(Social Science Edition), 2015(04):19-22;

[2] Xu T. Study of Relationship in Economic Growth, Environmental Quality and Industrial Structure in Shaanxi[J]. On Economic Problems, 2011(04):48-50;

[3] Zhang Y, Pan B L, Li J B et al. The relationship analysis between Chinese industrial water use and economic growth based on the Kuznets Curve[J]. Resources Science,2017(06):1118-1122;

[4] Li Y, Sun G N. Relationship between the process of industrialization and the atmosphere environment quality change in $\mathrm{X}$ i'an for 20 years[J]. Journal of Arid Land Resources and Environment, 2009(11):59-63; 